Article

\title{
Incidence and Levels of Deoxynivalenol, Fumonisins and Zearalenone Contaminants in Animal Feeds Used in Korea in 2012
}

\author{
Dong-Ho Kim ${ }^{1}$, In-Hye Lee ${ }^{2}$, Woo-Hyun Do ${ }^{2}$, Woo-Seon Nam ${ }^{2}$, Hua $\mathrm{Li}^{2}$, Han-Sub Jang ${ }^{2}$ and \\ Chan Lee ${ }^{2, *}$
}

1 National Agricultural Products Quality Management Service, Seoul 150-804, Korea;

E-Mail: anoldmu@korea.kr

2 School of Food Science and Technology, College of Natural Science, Chung-Ang University, Anseong-Si 456-756, Korea; E-Mails: dkr1313@naver.com (I.-H.L.);

dwh717@nate.com (W.-H.D.); nws0326@naver.com (W.-S.N.); lihua8272@nate.com (H.L.); jjhs@korea.kr (H.-S.J.)

* Author to whom correspondence should be addressed. E-Mail: chanlee@cau.ac.kr; Tel.: +82-31-670-4588; Fax: +82-31-676-8865.

Received: 23 September 2013; in revised form: 9 December 2013 / Accepted: 17 December 2013 / Published: 23 December 2013

\begin{abstract}
The objective of this study was to evaluate the occurrence and levels of deoxynivalenol (DON), fumonisins $\mathrm{B}_{1}$ and $\mathrm{B}_{2}(\mathrm{FBs})$, and zearalenone (ZEN) contaminants in animal feeds used in Korea in 2012. Contamination with DON was observed in $91.33 \%$ and $53.33 \%$ in compound feeds and feed ingredients, respectively. Among compound feeds, poultry layer feed (laying) exhibited the highest contaminant level of $1.492 \mathrm{mg} / \mathrm{kg}$. FBs contaminants were present in compound feeds and feed ingredients at $93.33 \%$ and $83.33 \%$, respectively. Most poultry broiler (early) feeds were highly contaminated with FBs, and one of these feeds detected the level as $12.823 \mathrm{mg} / \mathrm{kg}$ as the highest level. The levels of ZEN in compound feeds and feed ingredients were $71.33 \%$ and $47 \%$, respectively. Ninety-eight percent of compound feeds for cattle were contaminated with ZEN, and the highest contamination level of $0.405 \mathrm{mg} / \mathrm{kg}$ was observed in cattle fatting feeds.
\end{abstract}

Keywords: Fusarium; deoxynivalenol; fumonisin $\mathrm{B}_{1}$; fumonisin $\mathrm{B}_{2}$; zearalenone; compound feeds; feed ingredients 


\section{Introduction}

Members of the mycotoxin-producing fungal species, Fusarium, occur as facultative saprophytes and parasites. They are widespread in nature, and frequently contaminate many crops (corn, wheat, rye, oats, and rice) by producing a wide range of toxins [1]. The most hazardous Fusarium mycotoxins, in terms of animal health and productivity, are deoxynivalenol (DON), zearalenone (ZEN), fumonisins (FBs) and moniliformin [2].

DON, which is produced by F. graminearum [3] and F. culmorum [4], is one of the most common contaminants of corn, wheat, and barley worldwide. DON was characterized as a trichothecene and was given the name "vomitoxin" because of its emetic effect on swine [5,6]. FBs, which are diesters of propane-1,2,3-tricarboylic acid and various 2-amino-12,16-dimetylpolyhydroxyeicosanes, are natural contaminants in maize and maize-based feeds and foods worldwide. FBs such as $\mathrm{FB}_{1}, \mathrm{FB}_{2}$, and $\mathrm{FB}_{3}$ are particularly produced by $F$. verticillioides, and the related $F$. proliferatum [7]. FBs are commonly detected in foodstuffs such as corn, sorghum, asparagus, rice, beer, and beans. In long-term feeding studies, purified $\mathrm{FB}_{1}$ caused liver and kidney tumors in rodents [8]. ZEN is one of the most widely distributed mycotoxins produced by the Fusarium species $F$. graminearum and $F$. culmorum. It is found worldwide in various cereals such as maize, barley, wheat, and sorghum, and is classified as an estrogenic mycotoxin because it frequently uses hyperestrogenic syndrome in animals. ZEN-contaminated feed or grain, when consumed by livestock, can contribute to a wide variety of reproductive problems.

The presence of mycotoxins in grains and animal feeds has been reported worldwide for decades. Mycotoxin contamination of feed has become a major concern in animal feed science because it can cause acute or chronic mycotoxicosis in animals [9]. For these reasons, the regulation of mycotoxin levels in feed is of great interest, and the commission regulation of the European community set maximum levels (MLs) for FBs, DON, and ZEN in various animal feeds in 2007. Some countries in Asia, for example China and Japan, also have guidelines for these toxins in feeds. The MLs for FBs for complete feed in China was set to $0.500 \mathrm{mg} / \mathrm{kg}, 0.500 \mathrm{mg} / \mathrm{kg}$ for DON, and $0.100 \mathrm{mg} / \mathrm{kg}$ for ZEN. However, there are still no guideline values for these toxins in animal feed in Korea. This study therefore aimed to assess the occurrence and levels of DON, FBs, and ZEN in animal feeds distributed in South Korea in 2012, to better understand the contamination levels of mycotoxins in feeds.

\section{Results and Discussion}

\section{Contamination Levels}

Contamination Levels of DON in Compound Feeds and Feed Ingredients

As shown in Table 1, 100\% of the cattle feed samples were contaminated with DON, with the levels of contamination ranging from 0.131 to $1.000 \mathrm{mg} / \mathrm{kg}$. In swine feed, 44 out of 50 samples $(88 \%)$ were contaminated with DON, with levels of $0.037-0.982 \mathrm{mg} / \mathrm{kg}$, and a mean contamination level of $0.297 \mathrm{mg} / \mathrm{kg}$. The fatting growing (early) feed was contaminated with the highest levels of DON out of the swine feed samples. Eighty-six percent of the poultry feed samples were contaminated with DON, and the levels of contamination ranged from 0.035 to $1.492 \mathrm{mg} / \mathrm{kg}$, which was lower than that listed by commission regulation of the European Community. Consistent with these observations, Labuda et al. 
(2005) reported that $56 \%$ of poultry feed samples were contaminated with DON, and that the levels of contamination ranged from 0.064 to $1.230 \mathrm{mg} / \mathrm{kg}$, with a mean of $0.303 \mathrm{mg} / \mathrm{kg}$ [10].

Table 1. The presence of deoxynivalenol (DON) in compound feeds and feed ingredients.

\begin{tabular}{|c|c|c|c|c|c|c|c|}
\hline \multicolumn{4}{|c|}{ Samples } & \multirow{2}{*}{$\begin{array}{c}\text { Number }(\%) \\
\text { of DON } \\
\text { contaminated } \\
\text { samples }\end{array}$} & \multicolumn{3}{|c|}{ Concentration (mg/kg) } \\
\hline \multicolumn{2}{|r|}{ Type } & $\begin{array}{c}\text { Total } \\
\text { number }\end{array}$ & $\begin{array}{c}\text { Contaminated } \\
\text { number }\end{array}$ & & Minimum \pm SD & Maximum \pm SD & Mean \pm SD \\
\hline \multicolumn{8}{|c|}{ Cattle feeds } \\
\hline Breeding & Pregnancy & 5 & 5 & $\left(100^{\mathrm{b}}\right)$ & $0.225 \pm 0.030$ & $0.869 \pm 0.004$ & $0.463 \pm 0.248$ \\
\hline \multirow[t]{2}{*}{ Lactation } & Lactation & 11 & 11 & $\left(100^{b}\right)$ & $0.131 \pm 0.027$ & $1.000 \pm 0.084$ & $0.466 \pm 0.280$ \\
\hline & Calf & 11 & 11 & $\left(100^{b}\right)$ & $0.137 \pm 0.018$ & $0.942 \pm 0.066$ & $0.465 \pm 0.280$ \\
\hline \multirow[t]{4}{*}{ Fatting } & Calves & 11 & 11 & $\left(100^{b}\right)$ & $0.182 \pm 0.002$ & $0.943 \pm 0.148$ & $0.585 \pm 0.282$ \\
\hline & Finishing (earlyc) & 6 & 6 & $\left(100^{b}\right)$ & $0.213 \pm 0.008$ & $0.818 \pm 0.181$ & $0.470 \pm 0.256$ \\
\hline & Finishing (late $\left.{ }^{\mathrm{d}}\right)$ & 6 & 6 & $\left(100^{b}\right)$ & $0.187 \pm 0.036$ & $0.885 \pm 0.030$ & $0.642 \pm 0.334$ \\
\hline & Total & 50 & 50 & $\left(100^{b}\right)$ & & & \\
\hline \multicolumn{8}{|c|}{ Swine feeds } \\
\hline \multirow{4}{*}{ Breeding } & Piglets & 5 & 2 & $\left(40^{b}\right)$ & $0.046 \pm 0.002$ & $0.116 \pm 0.020$ & $0.081 \pm 0.049$ \\
\hline & Piglets $\geq 5 \mathrm{~kg}$ & 10 & 10 & $\left(100^{b}\right)$ & $0.114 \pm 0.011$ & $0.781 \pm 0.038$ & $0.325 \pm 0.223$ \\
\hline & Pregnancy & 10 & 10 & $\left(100^{b}\right)$ & $0.097 \pm 0.005$ & $0.732 \pm 0.011$ & $0.356 \pm 0.253$ \\
\hline & Lactation & 10 & 8 & $\left(80^{\mathrm{b}}\right)$ & $0.038 \pm 0.006$ & $0.843 \pm 0.057$ & $0.308 \pm 0.315$ \\
\hline \multirow[t]{3}{*}{ Fatting } & Growing (early $\left.{ }^{\mathrm{c}}\right)$ & 10 & 9 & $\left(90^{b}\right)$ & $0.037 \pm 0.024$ & $0.982 \pm 0.329$ & $0.321 \pm 5.032$ \\
\hline & Growing (late ${ }^{\mathrm{d}}$ ) & 5 & 5 & $\left(100^{b}\right)$ & $0.043 \pm 0.008$ & $0.492 \pm 0.014$ & $0.151 \pm 0.193$ \\
\hline & Total & 50 & 44 & $\left(88^{\mathrm{b}}\right)$ & & & \\
\hline \multicolumn{8}{|c|}{ Poultry feeds } \\
\hline \multirow[t]{2}{*}{ Layer } & Chicken & 15 & 15 & $\left(100^{b}\right)$ & $0.045 \pm 0.001$ & $1.097 \pm 0.201$ & $0.282 \pm 0.297$ \\
\hline & Laying & 11 & 10 & $\left(91^{\mathrm{b}}\right)$ & $0.035 \pm 0.008$ & $1.492 \pm 0.448$ & $0.255 \pm 0.452$ \\
\hline \multirow[t]{2}{*}{ Broiler } & Broiler (early $\left.{ }^{\mathrm{c}}\right)$ & 10 & 8 & $\left(80^{\mathrm{b}}\right)$ & $0.042 \pm 0.021$ & $0.139 \pm 0.023$ & $0.089 \pm 0.038$ \\
\hline & Broiler (late ${ }^{\mathrm{d}}$ ) & 9 & 7 & $\left(78^{\mathrm{b}}\right)$ & $0.051 \pm 0.026$ & $0.333 \pm 0.009$ & $0.145 \pm 0.096$ \\
\hline \multirow[t]{2}{*}{ Parent stock } & Breeder & 5 & 3 & $\left(60^{\mathrm{b}}\right)$ & $0.079 \pm 0.013$ & $0.749 \pm 0.181$ & $0.329 \pm 0.336$ \\
\hline & Total & 50 & 43 & $\left(86^{\mathrm{b}}\right)$ & & & \\
\hline \multicolumn{8}{|c|}{ Feed ingredients } \\
\hline \multirow{4}{*}{$\begin{array}{l}\text { Vegetable } \\
\text { proteins }\end{array}$} & Soybean meal & 2 & 0 & $(0)$ & & - & - \\
\hline & Corn gluten & 4 & 1 & $\left(25^{\mathrm{b}}\right)$ & $0.050 \pm 0.015$ & $0.050 \pm 0.015$ & $0.050 \pm 0.015$ \\
\hline & Corn germ meal & 2 & 2 & $\left(100^{\mathrm{b}}\right)$ & $0.083 \pm 0.005$ & $0.094 \pm 0.004$ & $0.089 \pm 0.007$ \\
\hline & Others $^{\mathrm{e}}$ & 10 & 6 & $\left(60^{b}\right)$ & $0.555 \pm 0.031$ & $0.957 \pm 0.003$ & $0.663 \pm 0.150$ \\
\hline \multirow[t]{2}{*}{ Bran } & Wheat bran & 1 & 0 & $(0)$ & - & - & - \\
\hline & Others $^{\mathrm{f}}$ & 8 & 7 & $\left(87.5^{\mathrm{b}}\right)$ & $0.075 \pm 0.012$ & $0.640 \pm 0.099$ & $0.421 \pm 0.232$ \\
\hline \multirow[t]{4}{*}{ Others } & By-products of food & 2 & 0 & $\left(0^{\mathrm{b}}\right)$ & - & - & - \\
\hline & Grain products & 1 & 0 & $(0)$ & - & - & - \\
\hline & Total & 30 & 16 & $\left(53.33^{\mathrm{b}}\right)$ & & & \\
\hline & Total & 180 & 153 & $\left(85^{b}\right)$ & & & \\
\hline
\end{tabular}

Notes: ${ }^{a}$ : Samples with DON concentrations $\geq \operatorname{LOQ}(0.035 \mathrm{mg} / \mathrm{kg})$ were used in the analyses; ${ }^{\mathrm{b}}:$ Concentration (\%); ${ }^{\mathrm{c}}:$ Early: under three months; ${ }^{\text {d: }}$ Late: 3 to 6 months; ${ }^{\text {e: }}$ Others: distillers dried grains, palm oil meal, coffee meal; ${ }^{\text {f: }}$ Others: corn gluten feed, wheat bran, cotton seeds hull, corn-bran, wheat shorts, wheat flour. 
Table 1 also explained DON contamination and 53.33\% of the feed ingredient samples were contaminated with DON, with a mean concentration of $0.447 \mathrm{mg} / \mathrm{kg}$, ranging from 0.050 to $0.957 \mathrm{mg} / \mathrm{kg}$. These levels were lower than those listed by the commission regulation of the European Community. The highest level of DON was observed in a vegetable protein samples $(0.957 \mathrm{mg} / \mathrm{kg})$ among all the feed ingredients tested. The contamination range of DON in feed ingredient samples was consistent with the observations of Binder et al. (2007), who analyzed feeds and feed ingredients for the presence of DON in North Asia [11]. Unlike aflatoxin $\mathrm{B}_{1}$, DON was highly prevalent in that region (71\%), and the highest level $(18.991 \mathrm{mg} / \mathrm{kg})$ was detected in a wheat sample sourced in China. In their study, the mean level of DON was $0.162 \mathrm{mg} / \mathrm{kg}$ and the level was lower than our study.

Consistent with the results in the present study, Monbaliu et al. (2010) reported that DON was detected in 52 samples with mean level of $0.949 \mathrm{mg} / \mathrm{kg}$ and 12 samples were contaminated with ZEN as mean level of $0.157 \mathrm{mg} / \mathrm{kg}$. The samples were collected from three EU countries; Czech Republic, Denmark, and Hungary. This report also presented the contamination of $\mathrm{FB}_{1}$ and $\mathrm{FB}_{2}$ in 36 and 29 samples with mean levels of 0.913 and $0.292 \mathrm{mg} / \mathrm{kg}$, respectively [12]. Several research articles reported that the levels of mycotoxins in compound feeds were lower than those observations in feed ingredients $[13,14]$ mainly due to the dilution of mycotoxins by cleaning and mixing steps during processing. However, in our previous reports related to contamination of Fusarium mycotoxin ( $\mathrm{FB}_{1}, \mathrm{FB}_{2}$, and beauvericin) in animal feeds in Korea, we also found higher contamination levels in compound feeds than those levels in feed ingredient $[15,16]$ as shown in the present study. This tendency can be explained by following two points of view. First, the contamination levels of Fusarium mycotoxins in animal feeds and feed ingredients in Korea are relatively lower than those observations in other countries or much the same $[4,10,11,18]$. Therefore, the tendency that the levels of contamination observed in compound feeds are higher than those reported for feed ingredient can be observed mainly due to the relatively lower contamination levels of Fusarium mycotoxins in feed ingredients. Second, several compound feeds in Korea contain corn-gluten feed (between $10 \%$ and $20 \%$ ) as a feed ingredient which showed the highest levels of Fusarium mycotoxin, as shown in "others" presented in Tables 1, 2 and 3. The addition of this feed ingredient could be the main reason why the levels of contamination observed in compound feeds are high compared with those levels in feed ingredients. Further study should be performed to explain this observation by investigation of storage conditions, processing steps and distribution of compound feeds in Korea.

\section{Contamination Levels of FBs in Compound Feeds and Feed Ingredients}

As shown in Table 2, FBs were detected in $98 \%$ of cattle feeds, at concentrations ranging from 0.042 to $2.990 \mathrm{mg} / \mathrm{kg}$. The lactation calf feed exhibited the highest contamination of $\mathrm{FB}_{\mathrm{S}}$, with a mean contamination level of $0.691 \mathrm{mg} / \mathrm{kg}$. Eighty-two percent of the 50 tested samples of swine feed were contaminated with FBs, with levels ranging from 0.037 to $5.509 \mathrm{mg} / \mathrm{kg}$. The breeding pregnancy feed was contaminated with the highest levels of FBs, and the mean level of contamination was $1.108 \mathrm{mg} / \mathrm{kg}$. These FBs levels were lower than the levels previously reported by our research group in animal feeds distributed in South Korea in 2011 [16] and they were all lower than those mentioned in the commission regulation of the European Community. However, Martins et al. (2011) reported that 8.7\% of swine feed samples in Portugal were contaminated with FBs in 2010, which is significantly lower than the percentage observed in this study [17]. All of the poultry feed samples were contaminated with FBs, 
and the contamination levels ranged from 0.092 to $12.823 \mathrm{mg} / \mathrm{kg}$, with a mean of $2.181 \mathrm{mg} / \mathrm{kg}$. Broiler (early) feeds contained the highest contamination with FBs, with mean levels of $3.459 \mathrm{mg} / \mathrm{kg}$. A similar contamination level of FBs was reported by Klarić et al. (2009) in Croatia with a mean level of $3.690 \mathrm{mg} / \mathrm{kg}$ in cereals and contaminated feed collected in 2007 from households of an endemic nephropathy area [18].

Table 2. The presence of fumonisins $\mathrm{B} 1$ and $\mathrm{B} 2$ (FBs) in compound feeds and feed ingredient samples.

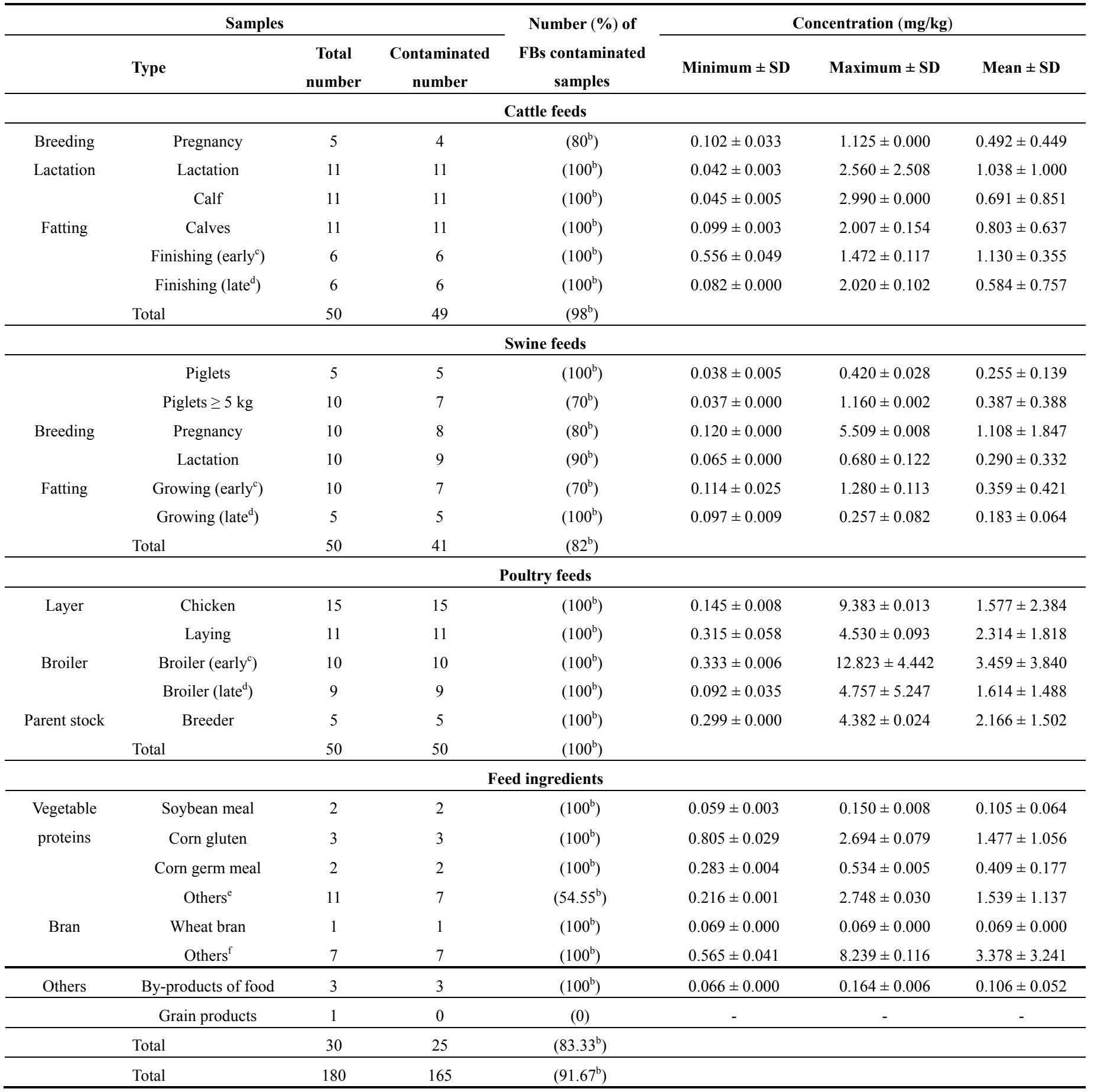

Notes: ${ }^{a}$ : Samples with $\mathrm{FB}_{1}$ concentrations $\geq \mathrm{LOQ}(0.030 \mathrm{mg} / \mathrm{kg})$ and $\mathrm{FB}_{2}$ concentrations $\geq \mathrm{LOQ}(0.035 \mathrm{mg} / \mathrm{kg})$ were used for analysis;

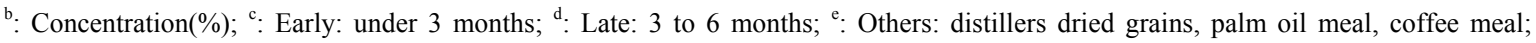

f: Others: corn gluten feed, wheat bran, cotton seeds hull, corn-bran, wheat shorts, wheat flour. 
Several research articles reported contamination of $\mathrm{FBs}$ in forms of $\mathrm{FB}_{1}$ and $\mathrm{FB}_{2}$, separately. In a study of simultaneous occurrence of $\mathrm{FB}_{1}$ in China, $\mathrm{Chu}$ and $\mathrm{Li}$ (1994) reported that the corn collected from two regions was heavily contaminated with $\mathrm{FB}_{1}$ at a mean level of $94 \mathrm{mg} / \mathrm{kg}$ [4]. In the investigation of Portuguese corn-based products, Waskiewicz et al. (2012) reported that $\mathrm{FB}_{1}$ was detected in all corn flour samples analyzed, and $\mathrm{FB}_{2}$ was detected in $70.7 \%$ of tested samples. The concentrations of $\mathrm{FB}_{1}$ and $\mathrm{FB}_{2}$ ranged from 0.050 to $1.300 \mathrm{mg} / \mathrm{kg}$, and $0.100-0.450 \mathrm{mg} / \mathrm{kg}$, respectively [19]. Consistent with other studies, the contamination levels of $\mathrm{FB}_{2}$ were lower than those of $\mathrm{FB}_{1}$ in all tested animal feeds and feed ingredients and all $\mathrm{FB}_{2}$ contaminated samples were co-contaminated with $\mathrm{FB}_{1}[20,21]$.

Table 2 also presented contamination of FBs in 25 feed ingredient samples (83.33\%), with lower contamination levels ranging from 0.059 to $8.239 \mathrm{mg} / \mathrm{kg}$, and a mean contamination level of $1.611 \mathrm{mg} / \mathrm{kg}$ compare with those observations in compound feeds. These levels were lower than the levels of FBs described by the commission regulation of the European Community. The data in these results were consistent with those reported by Binder et al. (2007), who assessed the presence of FBs $\left(\mathrm{FB}_{1}, \mathrm{FB}_{2}\right.$, and $\left.\mathrm{FB}_{3}\right)$ in feed ingredients in Asia and Oceania [11]. The highest level of contamination with FBs was found in a feed ingredient from China, with concentrations of $14.714 \mathrm{mg} / \mathrm{kg}$. The total contamination incidence in China was $16 \%$ in feed ingredients that were collected from the same regions.

Contamination Levels of ZEN in Compound Feeds and Feed Ingredients

ZEN was detected in $98 \%$ of the cattle feeds, with concentrations ranging from 0.009 to $0.405 \mathrm{mg} / \mathrm{kg}$ (Table 3). The fatting calves feed exhibited the highest contamination of ZEN, with a mean contamination of $0.194 \mathrm{mg} / \mathrm{kg}$. In the study of cattle feeds in Turkey, Kocasari et al. (2013) reported that ZEN was detected in $45.2 \%$ of tested samples at concentrations ranging from 0.002 to $0.029 \mathrm{mg} / \mathrm{kg}$ [21]. Sixty percent of the 50 swine feed samples were contaminated with ZEN, at concentrations ranging from 0.008 to $0.207 \mathrm{mg} / \mathrm{kg}$ at a mean of $0.036 \mathrm{mg} / \mathrm{kg}$. Out of the swine feed samples, breeding lactation feed was contaminated with the highest levels of ZEN. A total of $56 \%$ of the poultry feed samples were contaminated with ZEN, and the contamination levels ranged from 0.008 to $0.228 \mathrm{mg} / \mathrm{kg}$, with a mean of $0.041 \mathrm{mg} / \mathrm{kg}$. This level is lower than that listed in the commission regulation of the European Community. Consistent with our observations, Labuda et al. (2005) reported that $88 \%$ of poultry feed samples were contaminated with ZEN, and that levels ranged from 0.003 to $0.086 \mathrm{mg} / \mathrm{kg}$ (mean $0.021 \mathrm{mg} / \mathrm{kg}$ ) in Slovakia in 2004 [10].

Forty-seven percent of feed ingredients were contaminated with ZEN (14 feed ingredient samples out of 30 samples) at the concentrations range of $0.010-0.413 \mathrm{mg} / \mathrm{kg}$. The mean contamination level was $0.123 \mathrm{mg} / \mathrm{kg}$, which is lower than the levels of ZEN specified in the commission regulation of the European Community. Interestingly, all tested corn gluten and corn germ meal samples were contaminated with ZEN. Several researchers in different countries have reported the presence of ZEN in feed ingredients. Binder et al. (2007) analyzed the presence of ZEN in feed ingredients in Asia and Oceania [11], and reported mean ZEN contamination levels of $0.077 \mathrm{mg} / \mathrm{kg}$ in feed ingredients, which is comparable to our observations. The total incidence of contamination was $24 \%$ in feed ingredients that were collected from the same regions, which is much lower than those observed in this study. 
Table 3. The presence of zearalenone (ZEN) in compound feeds and feed ingredient samples.

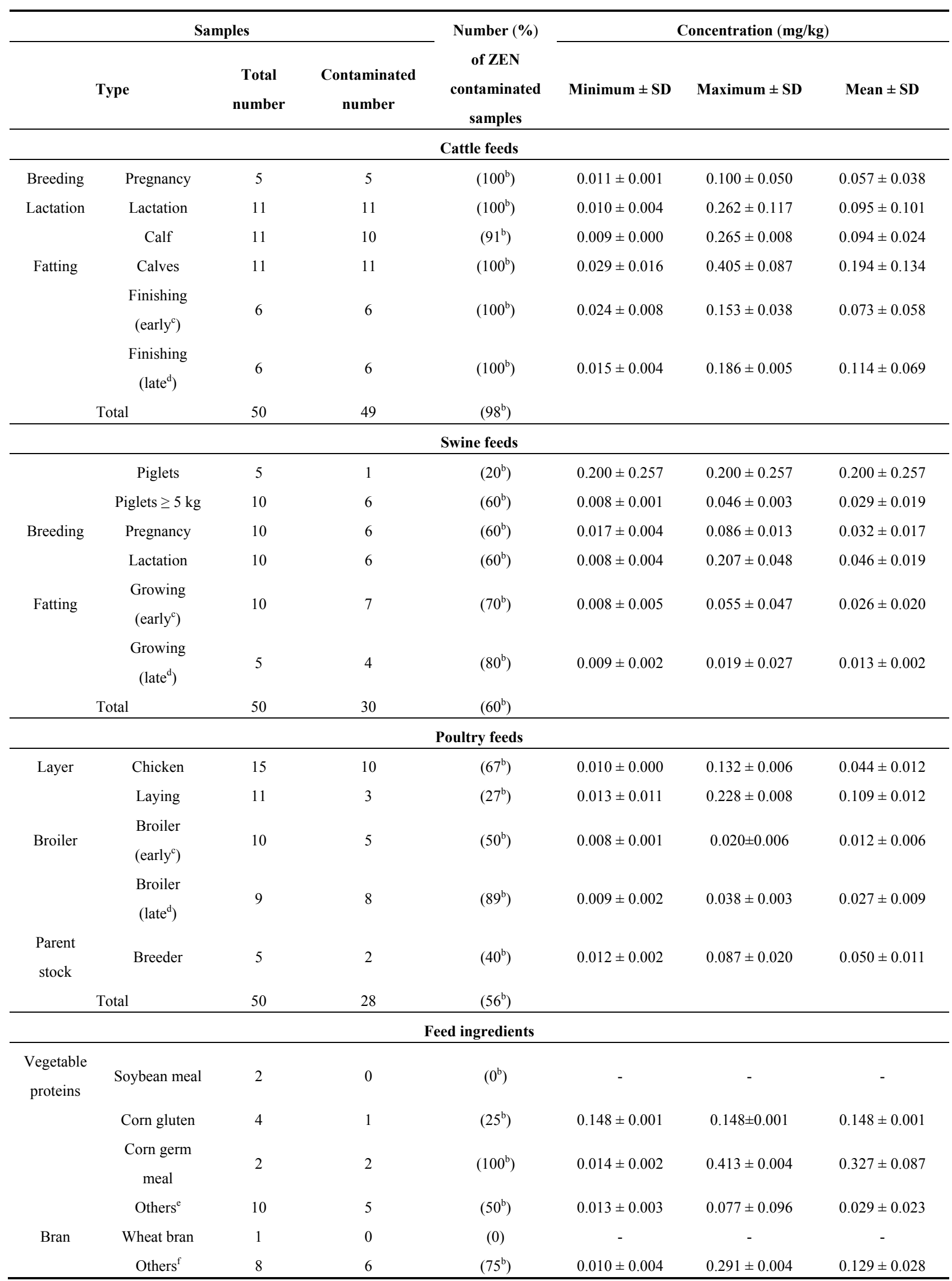


Table 3. Cont.

\begin{tabular}{|c|c|c|c|c|c|c|c|}
\hline \multicolumn{4}{|c|}{ Samples } & \multirow{2}{*}{$\begin{array}{c}\text { Number (\%) } \\
\text { of ZEN } \\
\text { contaminated } \\
\text { samples } \\
\end{array}$} & \multicolumn{3}{|c|}{ Concentration $(\mathrm{mg} / \mathrm{kg})$} \\
\hline \multirow{2}{*}{\multicolumn{2}{|c|}{ Type }} & $\begin{array}{c}\text { Total } \\
\text { number }\end{array}$ & $\begin{array}{c}\text { Contaminated } \\
\text { number }\end{array}$ & & Minimum \pm SD & Maximum \pm SD & Mean \pm SD \\
\hline & & \multicolumn{6}{|c|}{ Feed ingredients } \\
\hline \multirow[t]{4}{*}{ Others } & $\begin{array}{c}\text { By-products } \\
\text { of food }\end{array}$ & 1 & 0 & $(0)$ & & & \\
\hline & $\begin{array}{c}\text { Grain } \\
\text { products }\end{array}$ & 2 & 0 & (0) & - & - & - \\
\hline & Total & 30 & 14 & $\left(47^{b}\right)$ & & & \\
\hline & Total & 180 & 121 & $\left(67.22^{b}\right)$ & & & \\
\hline
\end{tabular}

Notes: ${ }^{a}$ : Samples with ZEN concentrations $\geq \operatorname{LOQ}(0.008 \mathrm{mg} / \mathrm{kg})$ were used for analysis; ${ }^{\mathrm{b}}$ : Concentration (\%); ${ }^{\mathrm{c}}$ : Early: under three

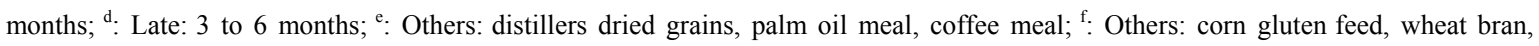
cotton seeds hull, corn-bran, wheat shorts, wheat flour.

Co-contamination of the Three Toxins in Compound Feeds and Feed Ingredients

Co-contamination of Fusarium mycotoxins is of great of interest as mycotoxigenic fungi are capable of producing more than one mycotoxin and feed raw materials might be infected with various fungal species. Thus, studying the occurrence of any given mycotoxin alone does not provide sufficient information about the risk associated with the respective feedstuffs [22]. Simultaneous occurrence of mycotoxins appears to exert greater negative effects on health and productivity than single mycotoxins [23], if there is no appropriate investigation, and management of mycotoxins in feeds and all relevant precautions have to be considered.

As illustrated in Table 4, most of the samples showed co-occurrence of mycotoxins at the same time. Cattle feeds showed the highest percentage of co-occurrence of mycotoxins followed by poultry feeds, swine feeds and ingredient samples. Some samples heavily contaminated with FBs or DON and usually contaminated with ZEN weakly. For example, one broiler (early) feed for poultry exhibited the maximum contamination level of FBs $(12.823 \mathrm{mg} / \mathrm{kg})$ were co-contaminated with the lower levels of DON $(0.139 \mathrm{mg} / \mathrm{kg})$ and ZEN $(0.020 \mathrm{mg} / \mathrm{kg})$. Other poultry feed for layer (laying) with the highest contamination level of DON $(1.492 \mathrm{mg} / \mathrm{kg})$ was also co-contaminated with FBs $(4.530 \mathrm{mg} / \mathrm{kg})$ and ZEN $(0.228 \mathrm{mg} / \mathrm{kg})$, respectively.

Table 4. Co-contamination of three toxins in animal feeds.

\begin{tabular}{ccccc}
\hline Categories & DON + FBs + ZEN & $\begin{array}{c}\text { The range of DON } \\
(\mathbf{m g} / \mathbf{k g})\end{array}$ & $\begin{array}{c}\text { The range of FBs } \\
(\mathbf{m g} / \mathbf{k g})\end{array}$ & $\begin{array}{c}\text { The range of ZEN } \\
(\mathbf{m g} / \mathbf{k g})\end{array}$ \\
\hline Cattle feeds & $48 / 50$ & $0.131-1.000$ & $0.042-2.990$ & $0.009-0.405$ \\
Swine feeds & $25 / 50$ & $0.037-0.982$ & $0.037-5.509$ & $0.008-0.207$ \\
Poultry feeds & $27 / 50$ & $0.035-1.492$ & $0.092-12.823$ & $0.008-0.228$ \\
Feed ingredient & $12 / 30$ & $0.050-0.957$ & $0.059-8.239$ & $0.010-0.413$ \\
Total & $112 / 180$ & & & \\
\hline
\end{tabular}




\section{Materials and Methods}

\subsection{Samples}

Compound feed and feed ingredient samples were collected from various regions in South Korea, and provided by the National Agriculture Products Quality Management Service Experiment Research Institute in 2012. The samples were prepared following the sampling guide in the code for the control of feeds (FAO/WHO 2004). One kilogram of sample was taken randomly from every ton of feed ingredients or compound feeds. Four different samples were pooled and divided into four groups, according to the sampling guide in the code for the control of feeds. Five hundred grams of the divided samples were tested for contamination with $\mathrm{DON}, \mathrm{FB}_{1}, \mathrm{FB}_{2}$, and $\mathrm{ZEN}$. The concentrations of DON, $\mathrm{FB}_{1}, \mathrm{FB}_{2}$, and $\mathrm{ZEN}$ were assessed in 150 samples of compound feeds, including cattle feed, swine feed, and poultry feed, and 30 samples of feed ingredients including vegetable proteins, and bran. The samples were stored at $4{ }^{\circ} \mathrm{C}$ before analysis to maintain the condition of the samples.

\subsection{Extraction and Purification of $D O N, F B_{S}$, and $Z E N$}

Feed samples were milled to obtain a particle size of $600 \mu \mathrm{M}$. DON was analyzed and validated as described in the Korean Food Standards Codex method (2010) for the determination of DON in corn and corn flakes. Twenty grams of each feed sample was extracted in $100 \mathrm{~mL}$ distilled water by homogenizing (OMNI MACRO ES HOMOGENIZER, USA) for $2 \mathrm{~min}$ at 10,000 rpm. The extract was then filtered through Whatman No. 6 filter paper, and $2.5 \mathrm{~mL}$ of filtered extract was applied to the immunoaffinity column (IAC; Vicam, DON test) containing specific antibodies for DON for

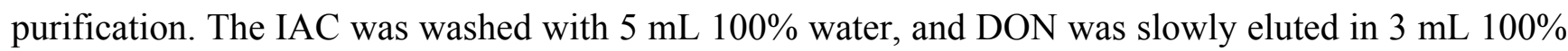
methanol at $1 \mathrm{drop} / \mathrm{s}$. The elute was collected and evaporated to dryness under nitrogen steam $\left(50{ }^{\circ} \mathrm{C}\right)$.

The analysis and validation of $\mathrm{FB}_{1}$ and $\mathrm{FB}_{2}$ were carried out in all samples according to the $\mathrm{AOAC}$ official method for the determination of fumonisins $B_{1}$ and $B_{2}$ (AOAC 2001). Twenty grams of feed sample was extracted with $100 \mathrm{~mL}$ of extraction solvent $(25: 25: 50$ methanol:acetonitrile:water, v/v/v) using a homogenizer for $2 \mathrm{~min}$ at $10,000 \mathrm{rpm}$. The extract was then filtered through Whatman No. 6 filter paper. Ten milliliters of the filtered extract was diluted in $40 \mathrm{~mL}$ phosphate-buffered saline (PBS; Sigma-Aldrich, St. Louis, MO, USA), and the diluted extracts were collected and purified through an IAC-containing fumonisin-specific antibodies. The IAC was rinsed with $10 \mathrm{~mL} \mathrm{PBS}$, and $\mathrm{FB}_{1}$ and $\mathrm{FB}_{2}$ were then eluted from the column using $4 \mathrm{~mL} 80 \%$ methanol at $1 \mathrm{drop} / \mathrm{s}$. The eluted fraction was evaporated to dryness under nitrogen steam at $60{ }^{\circ} \mathrm{C}$, and stored at $4{ }^{\circ} \mathrm{C}$ for derivatization before being analyzed by high-performance liquid chromatography (HPLC).

The ZEN assay and validation were performed as the Korean Food Standards Codex method (2010) for quantifying ZEN in corn and corn flakes. Twenty-five grams of each feed sample was extracted with $100 \mathrm{~mL} \mathrm{75 \%}$ acetonitrile containing $1 \mathrm{~mL}$ Tween 20 and $2 \mathrm{~g} \mathrm{NaCl}$ at 10,000 rpm for $5 \mathrm{~min}$. The extract was filtered through Whatman No.4 filter paper, and $10 \mathrm{~mL}$ filtered extract was diluted with $40 \mathrm{~mL}$ distilled water. Twenty-five milliliters of diluted extract was then purified using an IAC. The IAC was washed with $20 \mathrm{~mL}$ water at a flow-rate of 1 drop per second, and the elute was collected in $5 \mathrm{~mL}$ methanol and evaporated using nitrogen steam $\left(40^{\circ} \mathrm{C}\right)$. 


\subsection{HPLC Analysis}

For DON, the dried samples were re-dissolved in $0.5 \mathrm{~mL}$ of acetonitrile:water $(17: 83, \mathrm{v} / \mathrm{v})$. The samples $(20 \mu \mathrm{L})$ were analyzed using HPLC (Agilent Technology 1260 series; Agilent, Santa Rosa, CA, USA) equipped with an Agilent Technology 1200 Infinity UV Detector. An analytical column (ZORBAX Eclipse XDB-C18 column, $4.6 \times 250 \mathrm{~mm}, 5 \mu \mathrm{M}$, Agilent, USA) was used for HPLC analysis for $20 \mathrm{~min}$ at a constant flow rate of $1 \mathrm{~mL} / \mathrm{min}$ at $30^{\circ} \mathrm{C}$, and DON was detected at an absorbance of $220 \mathrm{~nm}$.

To analyze $\mathrm{FB}_{1}$ and $\mathrm{FB}_{2}$, the dried samples from $\mathrm{IAC}$ were re-dissolved in $0.5 \mathrm{~mL}$ acetonitrile:water $(50: 50, \mathrm{v} / \mathrm{v})$. Because this sample did not exhibit any fluorescence, it was derivatized using $o$-phthalaldehyde (OPA) reagent. Twelve microliters OPA was mixed with $10 \mu \mathrm{L}$ sample using an auto-program in the HPLC (Agilent Technology 1200 series; Agilent, USA) equipped with Agilent Technology 1260 Infinity Fluorescence Detector. The isocratic mobile phase (77:23 MeOH:0.1 M $\mathrm{NaH}_{2} \mathrm{PO}_{4}$, adjusted to $\mathrm{pH} 3.3$ with $\mathrm{H}_{3} \mathrm{PO}_{4}$ ) and analytical column (ZORBAX Eclipse XDB-C18 column, $4.6 \times 250 \mathrm{~mm}, 5 \mu \mathrm{M}$, Agilent, USA) were used for HPLC analysis for $30 \mathrm{~min}$ at a constant flow rate of $1 \mathrm{~mL} / \mathrm{min}$ at $30{ }^{\circ} \mathrm{C} . \mathrm{FB}_{1}$ and $\mathrm{FB}_{2}$ were detected by fluorescence with an excitation at $335 \mathrm{~nm}$ and emission at $440 \mathrm{~nm}$.

For ZEN, HPLC analysis was performed on an Agilent Technology 1200 series machine (Agilent, USA) for $20 \mathrm{~min}$ at a flow-rate of $1 \mathrm{~mL} / \mathrm{min}$. The mobile phase consisted of a mixture of methanol-water-acetonitrile (55:35:10, v/v/v), and an analytical column (ZORBAX Eclipse XDB-C18 column, $4.6 \times 250 \mathrm{~mm}, 5 \mathrm{~mm}$, Agilent, USA) was used for HPLC analysis. Twenty milliliters reconstituted extract was injected into the HPLC, and ZEN was measured (Agilent Technology 1260 Infinity Fluorescence Detector; Agilent, USA) with an excitation at $275 \mathrm{~nm}$ and emission at $450 \mathrm{~nm}$.

The analysis was done in duplication and the data was presented with \pm SD which indicated mean \pm SD of replication done on different samples of the same feed.

\subsection{Limit of Detection (LOD) and Limit of Quantification (LOQ)}

DON standard powder was purchased from Sigma-Aldrich (St. Louis, Mo, USA), and a standard solution of DON ( $1 \mathrm{mg} / \mathrm{mL})$ in $17 \%$ acetonitrile was stored in a sealed vial at $-20{ }^{\circ} \mathrm{C}$ until use. A standard solution of mixed $\mathrm{FB}_{1}$ and $\mathrm{FB}_{2}$ containing $50 \mu \mathrm{g} / \mathrm{mL}$ each mycotoxin was purchased from Sigma-Aldrich, and diluted in $50 \%$ acetonitrile to create $0.5 \mu \mathrm{g} / \mathrm{mL}$ standard solution, which was stored until needed to make a standard curve. ZEN standard powder was also purchased from Sigma Aldrich and, $1 \mathrm{mg}$ powder was dissolved in $100 \%$ acetonitrile as the stock solution, which was then further diluted in $100 \%$ acetonitrile to make the standard curve. The LOD was calculated at three times the signal-to-noise ratio, and LOQ was calculated at 10 times the signal-to-noise ratio.

The limit of detection (LOD) of DON was $0.010 \mathrm{mg} / \mathrm{kg}$, and the limit of quantification (LOQ) was $0.035 \mathrm{mg} / \mathrm{kg}$. Consistent with this, Bensassia et al. (2010) reported an LOD of $0.010 \mathrm{mg} / \mathrm{kg}$ and an LOQ of $0.030 \mathrm{mg} / \mathrm{kg}$ [24].

For $\mathrm{FB}_{1}$ and $\mathrm{FB}_{2}$, the LODs were 0.020 and $0.025 \mathrm{mg} / \mathrm{kg}$, respectively, and the LOQs were $0.030 \mathrm{mg} / \mathrm{kg}$ for $\mathrm{FB}_{1}$ and $0.035 \mathrm{mg} / \mathrm{kg}$ for $\mathrm{FB}_{2}$. In a previous study, Krska et al. (2007) reported that the LOD of FBs in feeds ranged from 0.010 to $0.050 \mathrm{mg} / \mathrm{kg}$ sample dry weights, which is consistent with our 
observations [25]. However, they reported LOQs of FBs in feeds in the range of $0.070-0.090 \mathrm{mg} / \mathrm{kg}$ [10], which is significantly higher than those reported from the present study.

For ZEN, the LOD and LOQ were $0.003 \mathrm{mg} / \mathrm{kg}$ and $0.008 \mathrm{mg} / \mathrm{kg}$, respectively. Previously, Eskola et al. (2002) reported an LOD of ZEN of $0.002 \mathrm{mg} / \mathrm{kg}$, and an LOQ of $0.003 \mathrm{mg} / \mathrm{kg}$ [26], which is lower than the LOD detected in our study.

\subsection{LC-MS/MS Analysis}

Liquid chromatography-tandem mass spectrometry (LC-MS/MS; Agilent HPLC, ABI 4000, USA) was used to confirm the type of DON and ZEN in the negative electrospray ionization (ESI-) mode, and $\mathrm{FB}_{1}$ and $\mathrm{FB}_{2}$ in the positive mode (ESI+). An analytical column (Imtakt Scherzo SM-C18) was used $(2.0 \times 150 \mathrm{~mm}, 3 \mu \mathrm{M})$ under gradient conditions with a flow rate of $0.25 \mathrm{~mL} / \mathrm{min}$ with the mobile phase consisting of $20 \%$ acetonitrile containing $2 \mathrm{mM}$ ammonium acetate, and acetonitrile containing $0.3 \%$ formic acid. Ten microliters sample was injected in to the HPLC and LC-MS/MS system, and the molecular weights of analyzed mycotoxins were compared with of the standard solutions. The source voltage was set in as $4.5 \mathrm{kV}$ at positive mode and $-4.5 \mathrm{kV}$ at negative mode with ion source temperature at $450{ }^{\circ} \mathrm{C}$. In the negative mode, the precursor ion $\left[\mathrm{M}+\mathrm{CH}_{3} \mathrm{COOH}\right]^{-}$of $\mathrm{DON}$ exhibited an $\mathrm{m} / \mathrm{z}$ value of 355.1 , with daughter product ions at 295.2 and $58.9 \mathrm{in} \mathrm{MS} / \mathrm{MS}$ analysis. In the positive mode, the precursor ion $[\mathrm{M}+\mathrm{H}]^{+}$of $\mathrm{FB}_{1}$ showed $\mathrm{m} / \mathrm{z}$ of 722.4 , which resulted in daughter product ions of 336.3 and 334.3 in MS/MS analysis. The EIC and MRM of $\mathrm{FB}_{2}$, in which the peak of precursor ion $[\mathrm{M}+\mathrm{H}]^{+}$was found at an $\mathrm{m} / \mathrm{z}$ value of 706.4 , with daughter product ions at 336.3 and 273.1 in the same mode of MS/MS analysis. ZEN in samples was detected as a peak of $\mathrm{m} / \mathrm{z} 317$, which was consistent with the $M / Z$ value of the $Z E N$ standard. The $M / Z$ values of the daughter product ions were 131.0 and 175.0 .

\section{Conclusions}

Among the tested compound feeds and feed ingredients, $91.67 \%$ of the animal feeds were contaminated with FBs. In addition, $85 \%$ were contaminated with DON, and $67.22 \%$ were contaminated with ZEN. The contamination levels of DON, FBs, and ZEN were 0.035-1.492, 0.037-12.823, and 0.008-0.413 mg/kg, respectively. This study revealed that the contamination levels of Fusarium mycotoxins (DON, FBs, and ZEN) were lower than the maximum levels set by the commission regulation of the European Community (EU 2006) except one sample for swine feed (FBs, $5.5 \mathrm{mg} / \mathrm{kg}$ ). However, the percentage of mycotoxin samples was noticeably high (67\%-92\%), suggesting that most animal feeds distributed in South Korea are contaminated. In addition, co-contamination of Fusarium mycotoxins in most samples makes it more concerning for animal health and reproduction and all relevant precautions have to be considered. Moreover, guidelines or maximum levels should not only be set for each mycotoxin individually but also for particularly concerning combinations of these toxins as it would be a more effective way to monitor feed safety in relation to mycotoxin contamination, and continuous monitoring of mycotoxins in feeds is therefore necessary for improving feed safety. 


\section{Acknowledgments}

This work was supported by the Basic Science Research Program through the National Research Foundation of Korea (NRF) funded by the Ministry of Education, Science and Technology (2012R1A2A2A01003635) and by the Chung-Ang University Excellence Student Scholarship.

\section{Conflicts of Interest}

The authors declare no conflict of interest.

\section{References}

1. Shier, W.T.; Badria, F.; Crepp, E.E. Cytotoxicity of fumonisin $B_{1}$ : Implication of lipid peroxidation and inhibition of protein and DNA syntheses. Arch. Toxicol. 1998, 72, 233-236.

2. D’Mello, J.P.F.; Macdonald, A.M.C.; Postel, D.; Hunter, E.A. 3-acetyl deoxynivalenol production in a strain of Fusarium culmorum insensitive to the fungicide difenoconazole. Mycotox. Res. 1997, $13,73-79$.

3. Miller, D.; Taylor, A.; Greenhalgh, R. Production of deoxynivalenol and related compounds in liquid culture by Fusarium graminearum. Can. J. Microbiol. 1983, 29, 1171-1178.

4. Greenhalgh, R.; Levandier, D. Production and characterization of deoxynivalenol and other secondary metabolites of Fusarium culmorum. J. Agric. Food Chem. 1986, 34, 98-102.

5. Jelinek, C.F.; Pohland, A.E.; Wood, G.E. Worldwide occurrence of mycotoxins in foods and feeds-an update. J. Assoc. Off. Anal. Chem. 1989, 72, 223-230.

6. Forsyth, D.M.; Yoshizawa, T.; Morooka, N.; Tuite, J. Emetic and refusal activity of deoxynivalenol to swine. Appl. Environ. Microb. 1977, 34, 547-552.

7. Creppy, E.E. Update of survey, regulation and toxic effects of mycotoxins in Europe. Toxicol. Lett. 2002, 127, 19-28.

8. Fun, S.C.; Guo, Y.L. Simultaneous occurrence of fumonisin $B_{1}$ and other mycotoxins in moldy corn collected from the People's Republic of China in regions with high incidences of esophageal cancer. Appl. Environ. Microb. 1994, 60, 847-852.

9. Placinta, C.M.; D’Mello, J.P.F.; Macdonald, A.M.C. A review of worldwide contamination of cereal grains and animal feed with Fusarium mycotoxins. Anim. Feed Sci. Technol. 1999, 78, 21-37.

10. Labuda, R.; Parich, A.; Berthiller, F. Incidence of trichothecenes and zearalenone in poultry feed mixtures from Slovakia. Int. J. Food Microbiol. 2005, 105, 19-25.

11. Binder, E.M.; Tan, L.M.; Chin, L.J.; Hnadl, J.; Richard, J. Worldwide occurrence of mycotoxins in commodities, feed and feed ingredients. Anim. Feed Sci. Technol. 2007, 132, 265-282.

12. Monbaliu, S.; Poucke, C.V.; Detavernier, C.; Dumoulin, F.; Velde, M.V.; Schoeters, E.; Dyck, S.V.; Averkieva, O.; Peteghem, C.V.; Saeger, S.D. Occurrence of mycotoxins in feed as analyzed by a multimycotoxin LC-MS/MS method. J. Agric. Food Chem. 2010, 58, 66-71.

13. Jindal, N.; Mahipal, S.K.; Rottinghaus, G.E. Occrrence of fumonisin $B_{1}$ in maize and poultry feeds in Haryana, India. Mycopathologia 1999, 148, 37-40. 
14. Prathapkumar, H.S.; Ramesh, V.B. Natural occurrence of fumonisin $B_{1}$ and its co-occurrence with aflatoxin $\mathrm{B}_{1}$ in Indian sorghum, maize and poultry feeds. J. Agric. Food Chem. 1997, 45, 2170-2173.

15. Kyungeun, L.; Byunghee, K.; Chan, L. Occurrence of Fusarium mycotoxin beauvericin in animal feeds in Korea. Anim. Feed Sci. Technol. 2010, 157, 190-194.

16. Donggeun, S.; Chanvorleak, P.; Chan, L. Occurrence of Fusarium mycotoxin fumonisin $\mathrm{B}_{1}$ and $\mathrm{B}_{2}$ in animal feeds in Korea. Mycotox. Res. 2013, 29, 159-167.

17. Almeida, I.; Martins, H.M. Co-occurrence of mycotoxins in swine feed produced in Portugal. Mycotox. Res. 2011, 27, 177-181.

18. Klarić, M.S.; Cvetnić, Z.; Pepelnjnak, S.; Kosalec, I. Co-occurrence of aflatoxins, ochratoxin A, fumonisins, and zearalenone in cereals and feed, determined by competitive direct enzyme-linked immunosorbent assay and thin-layer chromatography. Arh. Hig. Rada. Toksikol. 2009, 60, 427-434.

19. Waskiewicz, A.; Beszterda, M.; Golinski, P. Occurrence of fumonisisns in food-an interdisciplinary approach to the problem. Food Control 2012, 26, 491-499.

20. Chehri, K.; Jahromi, S.T.; Reddy, K.R.N. Occurrence of Fusarium spp. and fumonisins in stored wheat grains marketed in Iran. Toxins 2010, 2, 2816-2823.

21. Kocasari, F.S.; Mor, F.; Oguz, M.N. Occurrence of mycotoxins in feed samples in Burdur Province. Turkey Environ. Monit. Assess. 2013, 185, 4943-4949.

22. Elisabeth, S.; Gerd, S.; Panagiotis, T.; Eleni, T.; Daniela, M.; Ionelia, T.; Cristina, T.; Anca, N.; Iuliana, A.; Olivier, P.; et al. Current situation of mycotoxin contamination and co-occurrence in animal feed-focus on Europe. Toxins 2012, 4, 788-809.

23. Audrone, M.; Bronislava, B.; Zenonas, D. Peculiarities of cereal grain co-contamination with Fusarium mycotoxins. Zemdirbyste 2011, 4, 415-420.

24. Bensassia, F.; Zaieda, C.; Abida, S. Occurrence of deoxynivalenol in durum wheat in Tunisia. Food Control 2010, 21, 281-285.

25. Krska, R.; Welziga, E.; Boudra, H. Analysis of Fusarium toxins in feed. Anim. Feed Sci. Technol. 2007, 137, 241-264.

26. Eskola, M.; Kokkonen, M. Application of manual and automated systems for purification of ochratoxin A and zearalenone in cereals with immunoaffinity columns. J. Agric. Food Chem. 2002, 50, 41-47.

(C) 2013 by the authors; licensee MDPI, Basel, Switzerland. This article is an open access article distributed under the terms and conditions of the Creative Commons Attribution license (http://creativecommons.org/licenses/by/3.0/). 